\title{
Colour removal from beet molasses by ultrafiltration with activated charcoal
}

\section{Marta Bernal, María O. Ruiz*, Ramona M. Geanta, José M. Benito, Isabel Escudero}

Department of Biotechnology and Food Science, University of Burgos, Plaza Misael Bañuelos s/n, 09001 Burgos, Spain

*Corresponding author. Tel.: +34 947259561; fax: +34 947258831. E-mail address: moruiz@ubu.es

\begin{abstract}
The feasibility of an activated charcoal/ultrafiltration process for the decolouration of beet molasses, and subsequent regeneration of the exhausted charcoal by thermal and chemical methods, has been examined. Several activated charcoals were assayed prior to the selection of Norit powdered activated charcoal (NPAC). The affinity of NPAC for the adsorption of dark colour compounds was studied at $25^{\circ} \mathrm{C}$. A colour reduction of over $98 \%$ was achieved at equilibrium using a NPAC concentration of $5 \mathrm{~g} / \mathrm{L}$ from the beet molasses at $\mathrm{pH} 3$, with no betaine or sucrose coadsorptions. Crossflow ultrafiltration experiments with NPAC were performed using a $100 \mathrm{kDa}$ $\mathrm{TiO}_{2}$ tubular ceramic membrane, in order to select the optimal operating conditions. Experiments with several ultrafiltration stages for the decolouration of beet molasses, and subsequent regeneration of the exhausted NPAC with sodium hydroxide solutions, were also performed under the conditions identified previously. A high colour reduction in the molasses of over $96.5 \%$, with no adsorption of sucrose, betaine, citric acid or lactic acid, was achieved in the first decolouration stage at $\mathrm{pH} 3$, with an initial NPAC concentration of $5 \mathrm{~g} / \mathrm{L}$, a transmembrane pressure of $100 \mathrm{kPa}$ and a feed flowrate of $4.24 \mathrm{~L} / \mathrm{h}$. A good NPAC regeneration was obtained, with a loss of its colour removal capacity lower than $10 \%$.
\end{abstract}

Keywords: Beet molasses; Colour removal; Ultrafiltration; Activated charcoal; Regeneration 


\section{Introduction}

Beet molasses is mainly used as a supplement for livestock feed or as a substrate in fermentation processes, especially for ethanol and bioethanol productions [1-4]. This byproduct of sugar-beet processing plants is a highly viscous, dark brown syrup, which is characterised by a high content of fermentable sugars (50-55 wt.\%) and several non-sugar organic compounds, such as betaine, lactic acid, amino acids, minerals, phenolic compounds, and dark colour compounds (6 wt.\%) [1,5-7]. At least $80 \%$ of the colour of beet molasses is provided by melanins, melanoidins and hexose alkaline degradation products (HADPs), which can take part in sucrose hydrolysis and in many complex reactions such as Maillard reactions, with the formation of new melanoidins, and different polymerization reactions [2,6,8]. Removal of the dark colour compounds can be highly profitable in order to avoid changes to the composition and colour of beet molasses during storage and use $[1,3,7]$.

Activated charcoal has been extensively applied to remove colour and the colour precursors from several types of juices, coffee and tea infusions, sugar beet vinasses, vinegar, and syrups or liquors [9-15]. This adsorbent generally provides a high colour adsorption capacity without modifying the odour and flavour of the foods processed $[9,11]$.

Ultrafiltration with activated charcoal can be proposed as an alternative to conventional adsorption process in batch tanks or porous and fluidized beds in order to improve separation yield and to reduce processing costs. This hybrid technology combines the adsorption of coloured compounds by activated charcoal with an ultrafiltration to separate the decolourized stream and exhausted activated charcoal in a single stage. In this process both the membrane used to ensure total retention of the adsorbent and the regeneration process to allow reuse of the exhausted activated charcoal must be carefully selected. The most common techniques for regeneration of exhausted activated charcoal are thermal and chemical methods $[10,11,16-20]$. Thus, a temperature 
above $300{ }^{\circ} \mathrm{C}$ is usually used in thermal method [15] and water [11,18,19], sodium hydroxide solutions $[19,20]$ or various alcohols $[18,19]$ as desorption agents in chemical methods.

The main aim of this study was to evaluate the use of an activated charcoal/ultrafiltration process for the decolouration of beet molasses, and regeneration of the exhausted charcoal to recover the coloured compounds, thus allowing the activated charcoal to be reused. Colour removal from beet molasses can be useful to avoid changes in its composition during storage and to improve recovery processes for non-sugar compounds of market value such as betaine, lactic acid or phenolic compounds. Preliminary adsorption equilibrium isotherms were determined in order to select the type and minimum concentration of the activated charcoal, and the most suitable regeneration method for the exhausted activated charcoal. Continuous crossflow ultrafiltration experiments were performed using a tubular ceramic membrane, and the effects of transmembrane pressure (TMP), feed flowrate (Qf), feed $\mathrm{pH}$, initial NPAC concentration $\left(\mathrm{C}_{\mathrm{NPAC}}\right)$ and several feed types (water, molasses, molasses with NPAC) on the permeate flux, membrane fouling and colour reduction of beet molasses were investigated in order to select the optimal operating conditions. Experiments with ultrafiltration stages for the decolouration of beet molasses and subsequent chemical regeneration of the exhausted NPAC were also performed under the conditions identified previously. The colour reductions, co-adsorptions and loss of activated charcoal capacity after regeneration were calculated for this continuous process.

\section{Experimental section}

\subsection{Materials}

Anhydrous betaine ( $>98 \%$ purity, Fluka), lactic acid (>90\% purity, Fluka), citric acid $(>99.5 \%$ purity, Fluka), disodium hydrogen phosphate dodecahydrate (>98\%, Panreac), potassium dihydrogen phosphate (>99.5\%, Merck), maleic acid (99\%, Fluka), methanol (HPLC grade, HiPerSolv Chromanorm), sodium hydroxide (97\%, Panreac) and sucrose (99\%, Fluka) were used 
for analytical methods and cleaning processes. Laboratory grade chemicals without further purification were used as supplied in all cases. Solutions were prepared using Milli-Q water (Millipore, USA). Beet molasses containing 46.7 wt.\% sucrose, 3.8 wt.\% glucose, 4.0 wt.\% fructose, 7.6 wt. $\%$ betaine, 4.1 wt.\% lactic acid, 2.5 wt.\% citric acid, $1.0 \mathrm{wt} . \%$ phenolic compounds, and 16 wt.\% of moisture was supplied by a local sugar-beet factory. The molasses were diluted with water to $50 \mathrm{~g} / \mathrm{L}$, in order to lower their liquid density from $1408.0 \pm 0.4 \mathrm{~g} / \mathrm{L}$ to $1015.0 \pm 0.1 \mathrm{~g} / \mathrm{L}$ and their viscosity to $0.0011 \pm 0.0003 \mathrm{~Pa}$ s. The composition of the feed dilute molasses was $24.62 \pm$ $0.04 \mathrm{~mol} / \mathrm{m}^{3}$ lactic acid, $7.15 \pm 0.02 \mathrm{~mol} / \mathrm{m}^{3}$ citric acid, $30.30 \pm 0.01 \mathrm{~mol} / \mathrm{m}^{3}$ betaine, and $70.13 \pm$ $0.05 \mathrm{~mol} / \mathrm{m}^{3}$ sucrose, with an absorbance value of $1.30 \pm 0.01$ at $475 \mathrm{~nm}$, and a $\mathrm{pH}$ of $7.10 \pm 0.06$. Phosphoric acid (85\%, Sigma-Aldrich) was added to modify the $\mathrm{pH}$ of the dilute molasses from 7.1 to 1 or 3 .

Scharlau granular activated charcoal (Scharlau CA0346, Scharlab S.L), Scharlau powdered activated charcoal (Scharlau granular crushed with a volume mean diameter of $48.0 \pm 0.7 \mu \mathrm{m}$ ) and Norit powdered activated charcoal (Norit 97876, Sigma-Aldrich) were used to decolour the dilute molasses.

\subsection{Analytical methods}

The sucrose content of the molasses was measured by polarimetry at $880 \mathrm{~nm}$ using an Anton Paar MPC500 Sucromat polarimeter with a precision of $\pm 0.01^{\circ} \mathrm{Z}$ and reproducibility of $\pm 0.01^{\circ} \mathrm{Z}$ [7]. The colour of the feed molasses, decolourized molasses and exhausted charcoal regeneration solutions was determined spectrophotometrically at $475 \mathrm{~nm}$ using a Hitachi U-2000 spectrophotometer [21]. Total concentrations of betaine, lactic acid and citric acid in the molasses (feed and decolourized) were determined by liquid chromatography using a Beckman System Gold HPLC [7]. A reverse phase column ACE 5C18 (ACE HPLC columns), and a UV-vis detector at $216 \mathrm{~nm}$ were used. The mobile phase was an aqueous solution of 0.17 vol.\% phosphoric acid and 0.16 wt. $\%$ potassium di-hydrogen phosphate, with a flowrate of $1 \mathrm{~mL} / \mathrm{min}$. Maleic acid was used as 
an internal standard. Samples were analyzed in triplicate under identical conditions. The error in the HPLC analytical method was $\pm 0.01 \mathrm{~mol} / \mathrm{m}^{3}$.

The colour reduction $(\% \mathrm{D})$ of beet molasses and co-adsorption $(\% \mathrm{~A})$ of species $\mathrm{i}(\mathrm{i}=$ sucrose, lactic acid, citric acid or betaine) were calculated as follows:

$$
\begin{aligned}
& \% \mathrm{D}=100 \times\left(1-\frac{\mathrm{Abs}_{\mathrm{DM}}}{\mathrm{Abs}_{\mathrm{F}}}\right) \\
& \% \mathrm{~A}_{\mathrm{i}}=100 \times\left(1-\frac{\mathrm{C}_{\mathrm{i}_{\mathrm{DM}}}}{\mathrm{C}_{\mathrm{i}_{\mathrm{F}}}}\right)
\end{aligned}
$$

where Abs is the absorbance of samples measured at $475 \mathrm{~nm}, \mathrm{C}$ is the concentration expressed in $\mathrm{mol} / \mathrm{m}^{3}$, the subscripts $\mathrm{F}$ and DM refer to the feed molasses (initial condition) and the decolourized molasses after treatment with activated charcoal. The error in $\% \mathrm{D}$ was ranged from \pm 0.02 to \pm $0.8 \%$.

The $\mathrm{pH}$ of aqueous solutions (molasses and regeneration solutions) was measured using a Crison GLP 22 pH-meter fitted with an ATC 5531 temperature compensator and a Crison 52-08 electrode with an analytical error of $\pm 0.01 \mathrm{pH}$ units.

The antioxidant capacity of the feed molasses and the total permeate from the charcoal chemical regeneration was experimentally measured at a $\mathrm{pH}$ of 11 using a Hitachi U-2000 spectrophotometer at $517 \mathrm{~nm}$ and the DPPH (1-diphenyl-2-picrylhydrazyl) method, according to the method of Cheng et al. $[1,8,22]$ with TROLOX as standard. A blank was prepared for each sample. Samples were analyzed in triplicate under identical conditions. The error in the analytical method was $\pm 0.1 \mathrm{mmol} / \mathrm{g}$ of sample.

\subsection{Adsorption equilibrium isotherms}

All adsorption equilibrium isotherms were performed at $25 \pm 0.1{ }^{\circ} \mathrm{C}$ using $10 \mathrm{~mL}$ of the molasses diluted with water (50 g molasses/L) at a $\mathrm{pH}$ of 3.0 and 7.1 and different activated charcoal concentrations (1-10 g/L). Scharlau granular activated charcoal (SGAC), Scharlau powdered activated charcoal (SPAC), Norit powdered activated charcoal (NPAC) and NPAC after 
regeneration (by chemical and thermal methods) were used. Samples (molasses with activated charcoal) were shaken at $200 \pm 1 \mathrm{rpm}$ for $12-24$ hours in an Innova 2000 orbital shaker (New Brunswick Scientific Co) until equilibrium conditions had been achieved. The activated charcoal was separated by centrifugation (Eppendorf 5804 centrifuge) at $7500 \mathrm{rpm}$ for 15 minutes. The decolourized molasses was also filtered to remove any remains of charcoal. The separated phases (decolourized molasses and exhausted charcoal) were stored at $4{ }^{\circ} \mathrm{C}$. The feed molasses and decolourized molasses were analyzed experimentally to determine the colour reduction (Eq. 1), the co-adsorption of species i (Eq. 2) and $\mathrm{pH}$ changes. The loss of colour reduction capacity for activated charcoals after regeneration was estimated using the following equation:

$$
\text { Loss of } \% \mathrm{D}=100 \times\left(1-\frac{\% \mathrm{D}_{2}}{\% \mathrm{D}_{1}}\right)
$$

where $\% \mathrm{D}$ is the colour reduction of beet molasses calculated using Eq. 1 and subscripts 1 and 2 refer to the first decolouration stage with new activated charcoal and second decolouration stage with regenerated activated charcoal, respectively. The error in the loss of $\% \mathrm{D}$ was below $\pm 3 \%$.

\subsection{Exhausted NPAC regeneration experiments}

An adsorption equilibrium experiment at $25^{\circ} \mathrm{C}$ using $0.5 \mathrm{~L}$ of the dilute molasses at $\mathrm{pH} 3$ with 5 $\mathrm{g} / \mathrm{L}$ of NPAC was used to obtain exhausted NPAC. Regeneration of the exhausted NPAC was carried out by thermal, chemical, and combined chemical/thermal processes. Prior to regeneration, the exhausted NPAC was washed with water to avoid clumping due to the presence of sucrose, then dried in an oven (JP Selecta desktop oven to $250 \pm 0.25^{\circ} \mathrm{C}$ ) at $105 \pm 2{ }^{\circ} \mathrm{C}$.

Several dry exhausted-NPAC concentrations (5-50 g/L) and different desorption agents (water, ethanol and sodium hydroxide solutions) were used for chemical regeneration. Samples (desorption agent with the charcoal) were shaken at $200 \mathrm{rpm}$ for 6-12 hours at $25^{\circ} \mathrm{C}$ until equilibrium desorption conditions had been reached. The exhausted activated charcoal was then separated by centrifugation at $7500 \mathrm{rpm}$ for 15 minutes. Liquid samples were also filtered to remove traces of 
activated charcoal and the colour was experimentally measured. Equation 4 was used to determine the recovery of the colour compounds $\left(\% \mathrm{R}_{\text {colour }}\right)$ in desorption solutions $(\mathrm{S})$ at equilibrium with respect to the initial colour in the feed dilute molasses, prior to decolouration.

$$
\% \mathrm{R}_{\text {colour }}=100 \times\left(\frac{\mathrm{Abs}_{\mathrm{S}}}{\mathrm{Abs}_{\mathrm{F}}}\right)
$$

Thermal regeneration of the dry exhausted-NPAC $(0.3 \mathrm{~g})$ was performed in an oven at two temperatures $\left(450\right.$ and $\left.550^{\circ} \mathrm{C}\right)$ for several different times $(0.5,1,2$ and 5 hours). Charcoal weight loss after thermal treatment was determined gravimetrically using a Sartorius LA620S electronic scale $( \pm 0.001 \mathrm{~g})$. The experimental conditions for thermal regeneration experiments are collected in Table 1. Regeneration of the dry exhausted NPAC was also performed by chemical treatment with sodium hydroxide followed by thermal treatment at $450{ }^{\circ} \mathrm{C}$ for 30 minutes following the aforementioned procedure.

\subsection{Ultrafiltration of beet molasses with NPAC}

The experimental setup shown in Fig. 1 was used in ultrafiltration experiments. Filtanium ceramic membranes (Tami Industries) with an active layer of $\mathrm{TiO}_{2}$ supported on titania and a cutoff from 10 to $300 \mathrm{kDa}$ were used. These membranes consist of a single tubular module (length of $254 \mathrm{~mm}$, and inner and outer diameters of 6 and $10 \mathrm{~mm}$, respectively) with an effective membrane area, as stated by the manufacturer, of $47 \mathrm{~cm}^{2}$. The feed solution (acid water or molasses with NPAC) at $25 \pm 2{ }^{\circ} \mathrm{C}$ was pumped from a batch stirred glass tank (Pobel) to the membrane module using a Masterflex peristaltic pump (HV-7520-57, with a Masterflex L/S Easy-Load II Head HV77201-62). Silicone tubing (Masterflex L/S 15) was used. Prior to ultrafiltration, the feed solution (molasses with NPAC) was recirculated through the system without pressure for 30 minutes. The feed flowrate and transmembrane pressure were then adjusted to the desired values using a variable speed drive (from 1 to $100 \mathrm{rpm}$ ) for the pump and a valve placed after the membrane module. The pressures at the inlet and outlet of the membrane module were measured using two pressure gauges. 
Experiments were performed in concentration mode (the retentate was recycled back to the feed tank and the permeate was collected in the permeate tank). The activated charcoal concentration was increased progressively throughout the experiment. Permeate fluxes $\left(\mathrm{J}_{\mathrm{p}}\right)$ were determined gravimetrically using a Sartorius LA620S electronic scale $( \pm 0.001 \mathrm{~g})$ under different operating conditions of transmembrane pressure $(\mathrm{TMP}=50$ and $100 \mathrm{kPa})$, feed flowrate $(\mathrm{Qf}=1.86$ and 4.24 $\mathrm{L} / \mathrm{h}), \mathrm{pH}(1,3$ and 7.1$)$ and initial NPAC concentrations $\left(\mathrm{C}_{\mathrm{NPAC}}=1.5-5 \mathrm{~g} / \mathrm{L}\right)$. Two identical experiments with 3 and $5 \mathrm{~g} / \mathrm{L}$ of NPAC were performed in concentration mode to verify the reproducibility of the results. The permeates collected were also analyzed in order to determinate the colour removal (Eq. 1), co-adsorption of species i (Eq. 2), and changes in $\mathrm{pH}$ and membrane fouling. The initial conditions for ultrafiltration kinetic experiments are summarized in Table 2.

The ceramic membrane was cleaned at room temperature after each ultrafiltration run following a procedure that involved rinsing with soapy water and deionized water in order to remove the molasses and NPAC, cleaning with a $20 \mathrm{~g} / \mathrm{L}$ of $\mathrm{NaOH}$ solution in deionized water for 60 min at 30 $\mathrm{kPa}$, rinsing again with deionized water, and cleaning again with a 0.17 vol.\% aqueous $\mathrm{H}_{3} \mathrm{PO}_{4}$ solution at $30 \mathrm{kPa}$ for 60 minutes. The membrane was then rinsed with freshly deionized water and the permeate flux was measured at $25^{\circ} \mathrm{C}$ to check membrane cleaning.

Additional experiments with two consecutive ultrafiltration runs using several initial NPAC concentrations were performed to decolour the molasses at $\mathrm{pH} 3$. In the first run, the molasses plus NPAC ( 3 or $1.5 \mathrm{~g} / \mathrm{L}$ of NPAC1) mixture was crossflow ultrafiltered at $25 \pm 1{ }^{\circ} \mathrm{C}$ under the optimal conditions identified previously $(\mathrm{Qf}=4.24 \pm 0.06 \mathrm{~L} / \mathrm{h}$ and $\mathrm{TMP}=100 \pm 1 \mathrm{kPa})$. Ultrafiltration was performed in concentration mode for 3-4 hours to reach a total permeate (decolourized molasses) of $0.35 \mathrm{~L}$. The equipment and ceramic membrane were then cleaned following the procedure detailed above. The decolourized molasses was again added to the feed tank with a new quantity of weighed NPAC (3 g/L of NPAC2), then ultrafiltered in concentration mode under the same experimental conditions as the first ultrafiltration run. Permeate fluxes $\left(\mathrm{J}_{\mathrm{p}}\right)$ were also determined gravimetrically and analyzed using the aforementioned analytical methods. 
2.6. Decolouration of beet molasses with NPAC and NPAC after regeneration in the continuous charcoal/ultrafiltration process

Experiments with several ultrafiltration stages for decolouration of beet molasses and subsequent NPAC regeneration were performed. In the first decolouration stage, the feed of dilute molasses with NPAC (2.5 and $5 \mathrm{~g} / \mathrm{L}$ ) at $\mathrm{pH} 3$ was crossflow ultrafiltered (Fig. 1) at $25 \pm 2{ }^{\circ} \mathrm{C}$ using a feed flowrate of $4.24 \pm 0.06 \mathrm{~L} / \mathrm{h}$ and a TMP of $100 \pm 1 \mathrm{kPa}$. Ultrafiltration was performed in concentration mode for 1.7 hours to reach a total permeate (decolourized molasses) of $0.5 \mathrm{~L}$. The equipment containing exhausted NPAC was then rinsed with $2 \mathrm{~L}$ of water in order to remove traces of the molasses and sugars. Four NPAC regeneration runs were then carried out using sodium hydroxide solutions $(1 \mathrm{~mol} / \mathrm{L})$ for 4 hours. The equipment containing regenerated NPAC was then rinsed with $1 \mathrm{~L}$ of water and $2 \mathrm{~L}$ of aqueous $\mathrm{H}_{3} \mathrm{PO}_{4}$ solution at $\mathrm{pH} 3$ to restore the charge of the membrane and the adsorbent surface $[7,14,23]$. This operation was sufficient to achieve membrane cleaning. New dilute molasses at $\mathrm{pH} 3$ was then added to the feed tank and crossflow ultrafiltered under the same experimental conditions as the first decolouration run. In the experiment with an initial NPAC concentration of $5 \mathrm{~g} / \mathrm{L}$, two additional NPAC regeneration and molasses decolouration cycles were performed under the aforementioned conditions to evaluate the operational life of the activated charcoal. Prior to any ultrafiltration, solutions with NPAC were recirculated for 30 minutes without pressure. Two identical experiments were performed to verify the reproducibility of the results.

Permeate fluxes $\left(\mathrm{J}_{\mathrm{p}}\right)$ were determined gravimetrically and also analyzed using the aforementioned analytical methods. Colour reductions and loss of colour reduction capacity for the NPAC charcoal after regeneration were calculated using Eqs. 1 and 3, respectively. Equation 4 was used to determine recovery of the colour compounds $\left(\% \mathrm{R}_{\text {colour }}\right)$ in sodium hydroxide desorption solutions. 


\section{Results and discussion}

\subsection{Operating conditions for colour removal from beet molasses}

The $\mathrm{pH}$ is one of the main factors that affect the activated charcoal adsorption capacity due to the modification of its charge and the ionization equilibrium of many organic compounds dissolved in the feed aqueous molasses [14,23]. Preliminary equilibrium experiments were performed to select the most suitable activated charcoal and to determine the influence of $\mathrm{pH}$ on its colour adsorption capacity. The results of adsorption equilibrium isotherms using SGAC, SPAC and NPAC at a pH of 3 and 7.1 are shown in Figs. 2 and 3. Figure 2 shows that the best colour reduction was achieved using NPAC concentrations higher than $3 \mathrm{~g} / \mathrm{L}$ at $\mathrm{pH} 3$, with no co-adsorption (Fig. 3) of betaine and sucrose and a low co-adsorption of citric acid $(8.50 \pm 0.03 \%-10.00 \pm 0.05 \%)$ and lactic acid $(15.71 \pm 0.02 \%-16.77 \pm 0.04 \%)$ at equilibrium. In comparison with NPAC, a lower \%D (Fig. 2) and high co-adsorptions (not shown) of sucrose (45.03 $\pm 0.08 \%-56.1 \pm 0.1 \%)$ and citric acid $(35.0 \pm 0.1 \%-44.1 \pm 0.3 \%)$ were obtained with Scharlau powdered charcoal at $\mathrm{pH} 3$. Therefore, \%D for SPAC is affected by the high co-adsorption of sucrose and citric acid, so that we can conclude that Scharlau charcoal affinity by dark colour compounds is affected by the presence of other adsorbable compounds of the molasses. As such, NPAC was selected for subsequent experiments.

The particle size distribution of NPAC charcoal (see Fig. 4) was measured using laser light diffraction (Mastersizer 2000, Malvern Instruments Ltd.) and n-propanol (99\%, Prolabo) as dispersant medium. A particle size distribution (Fig. 4) from 0.8 to $500 \mu \mathrm{m}$ was obtained for NPAC with a volume mean diameter of $50.2 \pm 0.4 \mu \mathrm{m}$. Consequently, a tubular ceramic membrane with a $100 \mathrm{kDa}$ cut-off was used for crossflow ultrafiltration experiments to ensure total retention of NPAC.

The following step focused on evaluating the feasibility of continuous crossflow ultrafiltration with NPAC in order to select the optimal operating conditions for colour reduction in molasses of more than $90 \%$. Ultrafiltration permeates (decolourized molasses) were found to have the same $\mathrm{pH}$ 
and concentrations of species $i$ as the feed molasses (experiments 3-11 of Table 2), thus indicating that these species i were not adsorbed by NPAC present in the molasses due to its higher affinity by the dark colour compounds. Figure 5 shows the effects of the feed $\mathrm{pH}$, feed flowrate, initial NPAC, TMP and several feed types ( $\mathrm{F}=$ water, molasses, molasses with NPAC) on permeate flux (Fig. 5(a)) and colour removal (Fig. 5(b)) for the experiments of Table 2.

Constant permeate fluxes of $109.8 \pm 0.7 \mathrm{~kg} / \mathrm{m}^{2} \mathrm{~h}$ and $98 \pm 3 \mathrm{~kg} / \mathrm{m}^{2} \mathrm{~h}$ were obtained for systems with water at $\mathrm{pH} 3$ without NPAC (experiment 1) and with $3 \mathrm{~g} / \mathrm{L}$ of NPAC (experiment 2), respectively, as shown in Fig. 5(a). However, a continuous sharp decrease in $\mathbf{J}_{\mathrm{p}}$ is observed in Fig. 5(a) for experiments 3-11 with beet molasses, increasing slightly upon increasing the initial NPAC concentration from 0 to $5 \mathrm{~g} / \mathrm{L}$ (experiments 4-6 and 11), TMP from 50 to $100 \mathrm{kPa}$ (experiments 6 and 9), feed flowrate from 1.86 to $4.24 \mathrm{~L} / \mathrm{h}$ (experiments 6 and 10) and at pH 3 (experiments 6-8). These results indicate that the permeate flux is mainly affected by the molasses and, to a lesser extent, by the presence of NPAC in the feed solution, feed flowrate, TMP, or $\mathrm{pH}$.

Experiments 4-11 with beet molasses and NPAC (Fig. 5(b)) show that \%D also depend on the different operating conditions ( $\mathrm{pH}, \mathrm{TMP}, \mathrm{Qf}$ and $\left.\mathrm{C}_{\mathrm{NPAC}}\right)$ used. Thus, a comparison of experiments 6 $(\mathrm{pH} 3), 7(\mathrm{pH} 1)$ and $8(\mathrm{pH} 7.1)$ shows that $\% \mathrm{D}$ are higher at $\mathrm{pH} 3(\% \mathrm{D}=86.74 \pm 0.01 \%-89.08 \pm$ $0.01 \%)$ than at $\mathrm{pH} 1(\% \mathrm{D}=58.2 \pm 0.7-71.0 \pm 0.6 \%)$ or $7.1(\% \mathrm{D}=70.93 \pm 0.01 \%-72.02 \pm 0.01 \%)$. These kinetic results agree with the equilibrium results previously shown in Fig. 2.

It should be pointed out that permeates obtained in experiment 3 (molasses without NPAC) kept the same colour as the feed molasses, which indicates that the removal of coloured compounds (\%D) from the molasses is only due to their adsorptions on the activated charcoal, with no colour retention by the membrane. The effects of initial NPAC, TMP, and feed flowrate depicted in Fig. 5 (b) indicate that $\% \mathrm{D}$ also increase with increasing initial NPAC concentration from 1.5 to $5 \mathrm{~g} / \mathrm{L}$ (experiments 4-6 and 11), TMP from 50 to $100 \mathrm{kPa}$ (experiments 6 and 9) and, to a lesser extent, upon increasing the feed flowrate from 1.86 to $4.24 \mathrm{~L} / \mathrm{h}$ (experiments 6 and 10). A \%D about 97.24 
$\pm 0.01 \%$ after 3 hours is achieved using a pH of 3 , initial NPAC concentration of $5 \mathrm{~g} / \mathrm{L}$, TMP of 100 $\mathrm{kPa}$ and a feed flowrate of $4.24 \mathrm{~L}^{\prime} \mathrm{h}$, as can be observed from Fig. 5(b).

In addition, the linear fit (solid lines) of $\% \mathrm{D}$ experimental data (symbols) versus time is also shown in Fig. 5(b). The intercept and slope of the linear fit indicate, respectively, the colour reduction at the beginning of ultrafiltration and the colour removal rate, which can be assumed to be constant for each ultrafiltration experiment. The linear regression coefficients (r) and values for the slope (v) and intercept (\%Do) are also summarized in Table 2. A comparison of experiments 4-11 shows that $\mathrm{v}$ is mainly affected by the feed $\mathrm{pH}$, with values close to $1 \mathrm{~h}^{-1}$ (from 0.60 to $1.44 \mathrm{~h}^{-1}$ ) for systems with $\mathrm{pH} 3$, whereas \%Do depends on the $\mathrm{pH}$, initial NPAC and TMP. This result confirms that, in experiments at $\mathrm{pH} 3, \% \mathrm{D}$ increases with increasing $\%$ Do, reaching a maximum value of $95.80 \pm 0.02 \%$ at a TMP of $100 \mathrm{kPa}$ and initial NPAC concentration of $5 \mathrm{~g} / \mathrm{L}$.

Membrane fouling was also evaluated for the experiments of Table 2. Considering a resistancein-series model, the total resistance of the membrane can be written as [7,24]:

$$
\mathrm{R}_{\mathrm{t}}=\frac{\rho(\mathrm{TMP})}{\mu \mathrm{J}_{\mathrm{P}}}=\mathrm{R}_{\mathrm{m}}+\mathrm{R}_{\mathrm{S}}
$$

where $\rho$ and $\mu$ are the experimental density and viscosity of the solutions (water and molasses) listed in Table $2, \mathrm{R}_{\mathrm{m}}$ is the membrane hydraulic resistance expressed in $\mathrm{m}^{-1}$ and $\mathrm{R}_{\mathrm{S}}$ is the secondary resistance due to concentration polarization and membrane fouling, expressed in $m^{-1}$. As $R_{t}=R_{m}$ in systems with water, $\mathrm{R}_{\mathrm{m}}$ was measured experimentally for ultrafiltration of water and acidified water at pH 3 under different TMP values $(10-100 \mathrm{kPa})$ at $25^{\circ} \mathrm{C}$. A similar linear relationship between $\mathrm{J}_{\mathrm{p}}$ and TMP was observed for water and water at $\mathrm{pH} 3$. The experimental density and viscosity values for acidified water at pH 3 were $997.0 \pm 0.1 \mathrm{~kg} / \mathrm{m}^{3}$ and $0.89 \times 10^{-3} \pm 0.01 \times 10^{-3} \mathrm{~Pa}$ s, respectively. $R_{m}$ obtained from the slope of the linear fit of $J_{p}$ with TMP (not shown) was $3.66 \times 10^{12} \mathrm{~m}^{-1}$, with a linear regression coefficient of 0.9998 . The same value for $R_{m}\left(3.67 \times 10^{12} \pm 0.05 \times 10^{12} \mathrm{~m}^{-1}\right)$ was obtained from the experimental data of experiment 1 in Table 2 . The time evolution of $R_{t}$ and $R_{s}$ was calculated for experiments $2-11$ in Table 2 using Eq. 5. The contribution of the secondary 
resistance during each ultrafiltration experiment, expressed as $\%\left(\mathrm{R}_{\mathrm{s}} / \mathrm{R}_{\mathrm{t}}\right)$, is shown in Fig. 6 and Table 2. Figure 6 shows that $\mathrm{R}_{\mathrm{s}}$ increases with time for experiments with beet molasses at $\mathrm{pH} 3$. Similar results were obtained for the ultrafiltration of beet molasses at $\mathrm{pH} 1$ and 7.1, as shown in Table 2. As expected, $R_{s}$ is considerably higher than $R_{m}$ for these experiments with molasses, decreasing slightly upon increasing the initial NPAC from 0 to $5 \mathrm{~g} / \mathrm{L}$ at $\mathrm{pH} 3$, thus indicating that the molasses is the predominant contribution to the resistance (more than $60 \%$ for experiments at $100 \mathrm{kPa}$ ). This result reflects the formation of a dynamic membrane due to the activated charcoal deposited on the ceramic membrane surface, decreasing the effects of concentration polarization and ceramic membrane fouling promoted by the molasses [25-28]. As expected, TMP is an important parameter in the membrane fouling [28], increasing by about $40 \%$ upon increasing from 50 to $100 \mathrm{kPa}$. However, as higher values of $\mathrm{J}_{\mathrm{p}}$ and \%D were achieved with a TMP of $100 \mathrm{kPa}$, this value was selected for subsequent experiments, as discussed above. As an additional disadvantage, variations in TMP were detected in the experiment at $50 \mathrm{kPa}$ over time, thus meaning that TMP had to be readjusted to $50 \mathrm{kPa}$ throughout this experiment.

Figure 7 shows the colour reduction (\%D) of beet molasses at $\mathrm{pH} 3$ over time for experiments with two consecutive ultrafiltration runs using the molasses with 1.5 or $3 \mathrm{~g} / \mathrm{L}$ of NPAC (NPAC1) as feed in the first run and the permeate (decolourized molasses) from the first run with $3 \mathrm{~g} / \mathrm{L}$ of NPAC (NPAC2) as feed in the second run (ratios of NPAC1/NPAC2 $=1.5 / 3$ and 3/3). As expected, the $\% \mathrm{D}$ results for the first decolouration run were identical to those shown in Fig. 5(b) for experiments 4 and 6 of Table 2. In this first run, the molasses was decolourized by about $88.08 \pm$ $0.05 \%$ and $60.4 \pm 0.4 \%$ with an initial NPAC concentration of 3 and $1.5 \mathrm{~g} / \mathrm{L}$, respectively. A linear behaviour in $\% \mathrm{D}$ is also observed in the second decolouration run with values of $98.64 \pm 0.01 \%-$ $99.20 \pm 0.01 \%$ and $95.60 \pm 0.08 \%-96.10 \pm 0.08 \%$ for experiments with NPAC ratios of $3 / 3$ and $1.5 / 3$, respectively. Final molasses decolourization of $99.17 \pm 0.01 \%$ and $96.04 \pm 0.08 \%$ was achieved for experiments with NPAC ratios of $3 / 3$ and $1.5 / 3$, respectively, thus showing a high colour reduction in beet molasses even when using $1.5 \mathrm{~g} / \mathrm{L}$ of NPAC in the first ultrafiltration run. 


\subsection{Regeneration conditions for NPAC}

An important aim of this study is to evaluate the regeneration of the exhausted adsorbent by chemical and thermal methods for its reuse. As it was mentioned, chemical desorption experiments was carried out by using different exhausted NPAC concentrations (5-50 g/L) and several desorption agents (water, ethanol, $0.5 \mathrm{~mol} / \mathrm{L} \mathrm{NaOH}$ solutions, and $1 \mathrm{~mol} / \mathrm{L} \mathrm{NaOH}$ solutions). A negligible desorption was obtained with water and ethanol, an increased desorption $\left(\% \mathrm{R}_{\text {colour }}=\right.$ $69.97 \pm 0.01,71.97 \pm 0.03,20.4 \pm 0.3,17.28 \pm 0.02$, and $5.61 \pm 0.01$ for exhausted NPAC concentrations of $5,10,20,40$ and $50 \mathrm{~g} / \mathrm{L}$, respectively) was achieved with $0.5 \mathrm{~mol} / \mathrm{L} \mathrm{NaOH}$ solutions, whereas the use of $1 \mathrm{~mol} / \mathrm{L} \mathrm{NaOH}$ solutions using several exhausted NPAC concentrations gave the best desorption results $\left(\% \mathrm{R}_{\text {colour }}=95.04 \pm 0.05,145.85 \pm 0.08\right.$ and $201.84 \pm$ 0.03 for exhausted NPAC concentrations of 5, 10 and $20 \mathrm{~g} / \mathrm{L}$, respectively) for the dark coloured compounds. The removal of coloured compounds from the exhausted NPAC is then affected by the concentration of $\mathrm{NaOH}$ desorption solution and the concentration of exhausted NPAC used.

Thermal regeneration of exhausted NPAC was performed at two temperatures $\left(450{ }^{\circ} \mathrm{C}\right.$ and 550 $\left.{ }^{\circ} \mathrm{C}\right)$ and several different times (0.5-5 hours). The degree of decolouration $\left(\% \mathrm{D}_{1}\right.$ and $\% \mathrm{D}_{2}$, Eq. 1$)$ and loss of NPAC capacity values (Eq. 3) for colour removal after thermal regeneration under several experimental conditions are listed in Table 1. Some loss of activated charcoal was observed upon calcination, especially at $550{ }^{\circ} \mathrm{C}$. A high loss of $\% \mathrm{D}$ (about $50 \%$ ) was observed after the thermal regeneration at $550^{\circ} \mathrm{C}$ for $0.5-1$ hours and at $450^{\circ} \mathrm{C}$ for 5 hours. As shown in Table 1 , the best regeneration results were achieved at $450^{\circ} \mathrm{C}$ with times of less than 1 hour. The loss of NPAC adsorption capacity after this thermal regeneration was about $20 \%$ and $10 \%$ for NPAC concentrations of $3 \mathrm{~g} / \mathrm{L}$ and $5 \mathrm{~g} / \mathrm{L}$, respectively.

Figure 2 also shows a comparison of the adsorption equilibrium isotherms at $25^{\circ} \mathrm{C}$ for the dark colour removal of beet molasses at pH 3 using NPAC and NPAC regenerated by chemical (with 1 $\mathrm{mol} / \mathrm{L} \mathrm{NaOH}$ solutions), thermal (at $450{ }^{\circ} \mathrm{C}$ for 0.5 hours) and combined thermal/chemical 
processes (with $\mathrm{NaOH}$ solutions and at $450{ }^{\circ} \mathrm{C}$ for 0.5 hours). Similar equilibrium results were obtained by NPAC regenerated using thermal, chemical and combined thermal/chemical processes. These results show that the use of a thermal method at $450{ }^{\circ} \mathrm{C}$ with times of less than 1 hour does not provide significant improvements in terms of NPAC regeneration, which can be due to a low oxidation of NPAC with slight modifications in its surface activity and porosity [15].

Chemical regeneration method using $1 \mathrm{~mol} / \mathrm{L} \mathrm{NaOH}$ solutions and $10 \mathrm{~g} / \mathrm{L}$ of exhausted NPAC was selected for subsequent experiments to regenerate the exhausted activated charcoal, and also to recover the coloured compounds due to their high antioxidant capacity. Furthermore, differences in $\% \mathrm{D}$ for experiments with NPAC and regenerated NPAC were decreased upon increasing the initial NPAC concentrations from 1 to $5 \mathrm{~g} / \mathrm{L}$. The loss of NPAC decolouration capacity at equilibrium after these regeneration types was $33 \pm 3 \%, 25 \pm 2 \%$ and $11 \pm 1 \%$ using regenerated NPAC concentrations of 1,3 and $5 \mathrm{~g} / \mathrm{L}$, respectively. These results confirm that regeneration of activated charcoal depends on the initial NPAC concentration irrespective of the regeneration type used. Moreover, the loss of NPAC decolouration capacity after regeneration indicates that desorption is not completed and that the regeneration method may cause inactivation of active centres on the adsorbent particle [15,29].

3.3. Decolouration capacity for NPAC and NPAC after regeneration in the continuous charcoal/ultrafiltration process

In the first decolouration stage, the permeate flux and colour reduction $\left(\% \mathrm{D}_{1}=81.50 \pm 0.03-\right.$ $83.68 \pm 0.02$ and $95.82 \pm 0.01-97.35 \pm 0.02$ for experiments with $\mathrm{C}_{\mathrm{NPAC}}=2.5$ and $5 \mathrm{~g} / \mathrm{L}$, respectively) values over time were identical to those shown in Fig. 5(b) for experiments 5 and 11. The molasses was about $82.52 \pm 0.03 \%$ and $96.51 \pm 0.01 \%$ decolourized for systems with an initial NPAC concentration of 2.5 and $5 \mathrm{~g} / \mathrm{L}$, respectively. As expected, $\% \mathrm{D}$ for the second decolouration stage with regenerated NPAC was slightly lower and beet molasses achieved a lower colour reduction $\left(\% \mathrm{D}_{2}=66.10 \pm 0.04 \%\right.$ and $91.72 \pm 0.04 \%$ for experiments with $\mathrm{C}_{\mathrm{NPAC}}=2.5$ and $5 \mathrm{~g} / \mathrm{L}$, 
respectively). In Fig. 8 is depicted the time evolution for loss of decolouration capacity for NPAC after regeneration as calculated using Eq. 3. The loss of NPAC decolouration capacity varied from $1.83 \pm 0.07 \%$ to $9.09 \pm 0.05 \%$ in the system with $5 \mathrm{~g} / \mathrm{L} \mathrm{NPAC}$ and from $7.31 \pm 0.05 \%$ to $23.00 \pm$ $0.08 \%$ in the system with $2.5 \mathrm{~g} / \mathrm{L}$ NPAC. These results are in good agreement with the equilibrium data for regenerated NPAC shown in Fig. 2. A colour reduction $\left(\% \mathrm{D}_{3}=91.1 \pm 0.1 \%\right.$ and $\% \mathrm{D}_{4}=$ $91.4 \pm 0.2 \%)$ for molasses similar to the $\% \mathrm{D}_{2}(91.72 \pm 0.04)$ value was achieved in two successive decolouration stages using the system containing $5 \mathrm{~g} / \mathrm{L}$ of NPAC. These results show that, even after several regeneration cycles, NPAC maintains the slight loss in colour reduction capacity obtained in the first regeneration run.

Regeneration of exhausted NPAC after the first adsorption stage was performed by ultrafiltration using four desorption runs with sodium hydroxide solutions ( $1 \mathrm{~mol} / \mathrm{L})$. The colour of desorption permeates $\left(\mathrm{Abs}_{\mathrm{S}}\right)$ was measured experimentally throughout the ultrafiltration experiment. Figure 9 shows the recovery of the coloured compounds (\% $\mathrm{R}_{\text {colour }}$, Eq. 4) in $\mathrm{NaOH}$ desorption solutions.

Similar colour-desorption were obtained for both systems studied, with any differences being due to the different degree of exhaustion of the activated charcoal after the first decolouration stage. Good NPAC regeneration was obtained in these experiments, as shown in Fig. 9. A value higher than $50 \%$ for the first desorption run and a total desorption close to $93.6 \pm 0.1 \%$ were achieved for the experiment with an initial NPAC concentration of $5 \mathrm{~g} / \mathrm{L}$. An important feature was that the total permeate from the first desorption run containing $40-50 \%$ of the dark colour of the feed molasses had about $20 \%\left(17.5 \%\right.$ and $25 \%$, respectively, for experiments with $\mathrm{C}_{\mathrm{NPAC}}=2.5$ and $\left.5 \mathrm{~g} / \mathrm{L}\right)$ of the antioxidant capacity of the molasses. Similar desorption results were obtained in the subsequent regeneration cycles for the system with $5 \mathrm{~g} / \mathrm{L}$ NPAC (not shown).

Moreover, as $\mathbf{J}_{\mathrm{p}}$ was completely restored without additional cleaning cycles, we can conclude that this continuous process allows a high decolouration of beet molasses and good NPAC regeneration without the need for equipment disassembly or other membrane-cleaning cycles. 


\section{Conclusions}

The capacity of several activated charcoals to adsorb dark colour compounds from dilute beet molasses was studied in equilibrium experiments and NPAC was selected. A fast colour removal of more than $97 \%$ after 3 hours, with no co-adsorption of sucrose, betaine, citric acid or lactic acid, was achieved for the crossflow ultrafiltration experiment using feed molasses at $\mathrm{pH} 3$, an initial NPAC concentration of $5 \mathrm{~g} / \mathrm{L}$, a $100 \mathrm{kDa} \mathrm{TiO}_{2}$ tubular ceramic membrane, a TMP of $100 \mathrm{kPa}$, and a feed flowrate of $4.24 \mathrm{~L} / \mathrm{h}$. The removal of coloured compounds was only due to their adsorption on NPAC dynamic membrane formed onto the ceramic membrane surface, which also helped to the decrease of concentration polarization and ceramic membrane fouling promoted by the molasses. Experiments with several ultrafiltration stages for the decolouration of beet molasses with an initial NPAC concentration of 2.5 or $5 \mathrm{~g} / \mathrm{L}$ and subsequent regeneration of the exhausted NPAC with $\mathrm{NaOH}$ solutions were performed under the optimal operating conditions. The molasses was decolourized by about $96.5 \%$ in the first adsorption stage when using an initial NPAC concentration of $5 \mathrm{~g} / \mathrm{L}$. A good NPAC regeneration was also obtained, with a loss of its colour removal capacity lower than $10 \%$ for three consecutive ultrafiltration runs, with no need for equipment disassembly or other membrane-cleaning cycles. Moreover, the lower cost of activated charcoals compared with other adsorbents, together with their good regeneration capacity with $\mathrm{NaOH}$ solutions suggest the use of this NPAC/ultrafiltration process from a technical, economic, and environmental viewpoint.

\section{Nomenclature}

Abs absorbance of samples (molasses and desorption samples) measured at $475 \mathrm{~nm}$

$\mathrm{A}_{\mathrm{i}} \quad$ co-adsorption of species $\mathrm{i}$ on the activated charcoal defined in Eq. 2

$\mathrm{C}_{\mathrm{i}} \quad$ concentration of species $\mathrm{i}\left(\mathrm{mol} / \mathrm{m}^{3}\right)$

$\mathrm{C}_{\mathrm{NPAC}} \quad$ concentration of Norit powdered activated charcoal $(\mathrm{g} / \mathrm{L})$

D colour reduction of the molasses defined in Eq. 1. 


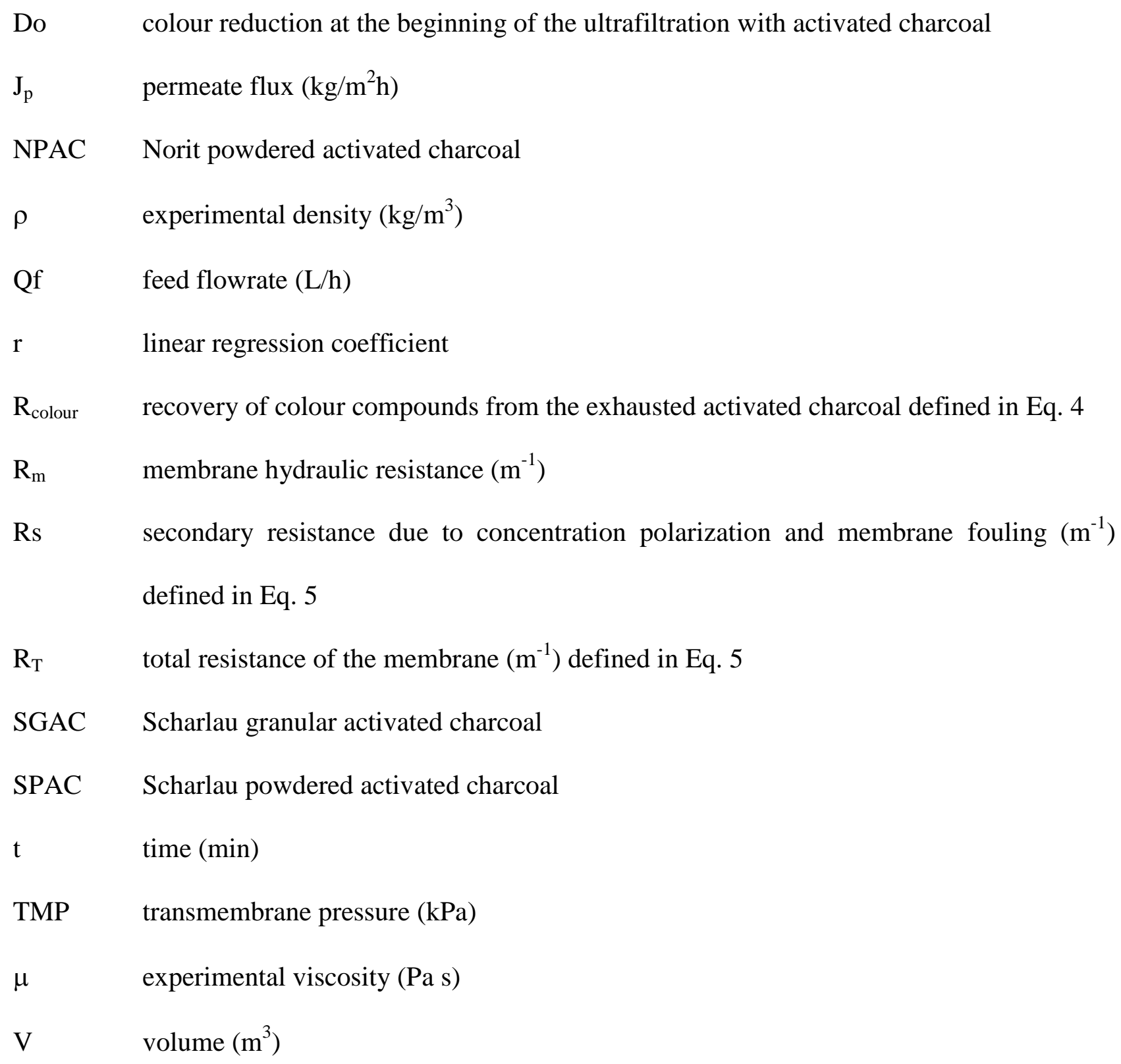




\section{Acknowledgements}

Financial support from the Ministerio de Economía y Competitividad (MINECO, Spain) through project CTQ2011-25239 and from the Junta de Castilla y León through project BU175A112 is gratefully acknowledged. Ramona M. Geanta would also like to thank the Junta de Castilla y León and the European Social Fund for grant EDU 1933/2008 in support of her PhD.

\section{References}

[1] V. Valli, A.M. Gómez-Caravaca, M. Di Nunzio, F. Danesi, M.F. Caboni, A. Bordoni, Sugar cane and sugar beet molasses, antioxidant-rich alternatives to refined sugar, J. Agric. Food Chem. 60 (2012) 12508-12515.

[2] M. Coca, M.T. García, S. Mato, A. Cartón, G. González, Evolution of colorants in sugarbeet juices during decolorization using styrenic resins, J. Food Eng. 89 (2008) 429-434.

[3] R. Razmovski, V. Vučurović, Bioethanol production from sugar beet molasses and thick juice using Saccharomyces cerevisiae immobilized on maize stem ground tissue, Fuel 92 (2012) 18.

[4] C.M. Guimarães, M.S. Gião, S.S. Martinez, A.I. Pintado, M.E. Pintado, L.S. Bento, F.X. Malcata, Antioxidant activity of sugar molasses, including protective effect against DNA oxidative damage, J. Food Sci. 72 (2007) 39-43.

[5] M.-L. Lameloise, R. Lewandowski, Purification of beet molasses by ion-exclusion chromatography: fixed-bed modeling, J. Chromatogr. A 685 (1994) 45-52.

[6] M. Coca, M.T. García, G. González., M. Peña, J.A. García, Study of coloured components formed in sugar beet processing, Food Chem. 86 (2004) 421-433.

[7] R.M. Geanta, M.O. Ruiz, I. Escudero, Micellar-enhanced ultrafiltration for the recovery of lactic acid and citric acid from beet molasses with sodium dodecyl sulphate, J. Membr. Sci. 430 (2013) 11-23. 
[8] B. Payet, A.S.C. Sing, J. Smadja, Comparison of the concentrations of phenolic constituents in cane sugar manufacturing products with their antioxidant activities, J. Agric. Food Chem. 54 (2006) 7270-7276.

[9] Y. Satyawali, M. Balakrishnan, Removal of color from biomethanated distillery spentwash by treatment with activated carbons, Bioresour. Technol. 98 (2007) 2629-2635.

[10] R.R. Bansode, J.N. Losso, W.E. Marshall, R.M. Rao, R.J. Portier, Pecan shell-based granular activated carbon for treatment of chemical oxygen demand (COD) in municipal wastewater, Bioresour. Technol. 94 (2004) 129-135.

[11] S.C. Panchangam, K. Janakiraman, Sorptive removal of color from aqueous coffee and tea infusions, Desalin. Water Treat. 50 (2012) 338-347.

[12] S.G. Karp, A.H. Igashiyama, P.F. Siqueira, J.C. Carvalho, L.P.S. Vandenberghe, V. ThomazSoccol, J. Coral, J.-L. Tholozan, A. Pandey, C.R. Soccol, Application of the biorefinery concept to produce L-lactic acid from the soybean vinasse at laboratory and pilot scale, Bioresour. Technol. 102 (2011) 1765-1772.

[13] J. Shen, I. Kaur, M.M. Baktash, Z. He, Y. Ni, A combined process of activated carbon adsorption, ion exchange resin treatment and membrane concentration for recovery of dissolved organics in pre-hydrolysis liquor of the kraft-based dissolving pulp production process, Bioresour. Technol. 127 (2013) 59-65.

[14] V. Caqueret, S. Bostyn, B. Cagnon, H. Fauduet, Purification of sugar beet vinasse -Adsorption of polyphenolic and dark colored compounds on different commercial activated carbons, Bioresour. Technol. 99 (2008) 5814-5821.

[15] F. López, F. Medina, M. Prodanov, C. Güell, Oxidation of activated carbon: application to vinegar decolorization, J. Colloid Interface Sci. 257 (2003) 173-178.

[16] D. Guoa, Q. Shia, B. Hea, X. Yuanb, Different solvents for the regeneration of the exhausted activated carbon used in the treatment of coking wastewater, J. Hazard. Mater. 186 (2011) 1788-1793. 
[17] J.-L. Lim, M. Okada, Regeneration of granular activated carbon using ultrasound, Ultrason. Sonochem. 12 (2005) 277-282.

[18] A. Simaratanamongkol, P. Thiravetyan, Decolorization of melanoidin by activated carbon obtained from bagasse bottom ash, J. Food Eng. 96 (2010) 14-17.

[19] R.J. Martin, W.J. Ng, Chemical regeneration of exhausted activated carbon-I, Water Res. 18 (1984) 59-73.

[20] P.-J. Lu, H.-C. Lin, W.-T. Yu, J.-M. Chern, Chemical regeneration of activated carbon used for dye adsorption, J. Taiwan Inst. Chem. Eng. 42 (2011) 305-311.

[21] M. Peña, M. Coca, G. González, R. Rioja, M.T. García, Chemical oxidation of wastewater from molasses fermentation with ozone, Chemosphere 51 (2003) 893-900.

[22] Z. Cheng, J. Moore, L. Yu, High-throughput relative DPPH radical scavenging capacity assay, J. Agric. Food Chem. 54 (2006) 7429-7436.

[23] R. Ocampo-Pérez, F. Orellana-Garcia, M. Sánchez-Polo, J. Rivera-Utrilla, I. Velo-Gala, M.V. López-Ramón, M.A. Álvarez-Merino, Nitroimidazoles adsorption on activated carbon cloth from aqueous solution, J. Colloid Interface Sci. 401 (2013) 116-24.

[24] F.V. da Silva, N.U. Yamaguchi, G.A. Lovato, F.A. da Silva, M.H.M. Reis, M.T.P.S. de Amorim, C.R.G. Tavares, R. Bergamasco, Effects of coconut granular activated carbon pretreatment on membrane filtration in a gravitational driven process to improve drinking water quality, Environ. Technol. 33 (2012) 711-716.

[25] J. Ma, Z. Wang, Y. Xu, Q. Wang, Z. Wu, A. Grasmick, Organic matter recovery from municipal wastewater by using dynamic membrane separation processes, Chem. Eng. J. 219 (2013) 190-199.

[26] Y. Pan, T. Wang, H. Sun, W. Wang, Preparation and application of titanium dioxide dynamic membranes in microfiltration of oil-in-water emulsions, Sep. Purif. Technol. 89 (2012) 78-83.

[27] M.T. Pessoa de Amorim, I.R.A. Ramos, Control of irreversible fouling by application of dynamic membranes, Desalination 192 (2006) 63-67. 
[28] C. Tansakul, S. Laborie, C. Cabassud, Adsorption combined with ultrafiltration to remove organic matter from seawater, Water Res. 45 (2011) 6362-6370.

[29] Y. Zhang, J. Tian, J. Nan, S. Gao, H. Liang, M. Wang, G. Li, Effect of PAC addition on immersed ultrafiltration for the treatment of algal-rich water, J. Hazard. Mater. 186 (2011) $1415-1424$. 


\section{Figure captions}

Figure 1. Experimental setup for ultrafiltration experiments with activated charcoal.

Figure 2. Adsorption equilibrium isotherms at $25{ }^{\circ} \mathrm{C}$ for the colour removal from dilute beet molasses (50 $\mathrm{g}$ of molasses/L) at two $\mathrm{pH}$ values (3 and 7.1) with several activated charcoals (SGAC, SPAC, NPAC and NPAC regenerated by chemical (with NaOH solutions), thermal (at 450 ${ }^{\circ} \mathrm{C}$ for 0.5 hours) and combined thermal/chemical processes) and different activated charcoal concentrations $(1-10 \mathrm{~g} / \mathrm{L})$.

Figure 3. Equilibrium co-adsorption of species i ( $\mathrm{i}=$ sucrose, betaine or carboxylic acids) for experiments of Fig. 2 with NPAC at $\mathrm{pH} 3$ and 7.1.

Figure 4. Particle size distribution for Norit powdered activated charcoal (NPAC).

Figure 5. Time evolution of (a) the permeate flux $\left(\mathrm{J}_{\mathrm{p}}\right)$ and (b) colour reductions (\%D) for ultrafiltration kinetic experiments 1-11 in Table 2. Experimental values of \%D (symbols) calculated using Eq. 1 and their linear fit (lines). Linear regression coefficients, slopes and intercepts of the linear fit can be found in Table 2 .

Figure 6. Comparison of the contribution of secondary resistances $\left(\%\left(\mathrm{R}_{\mathrm{s}} / \mathrm{R}_{\mathrm{t}}\right)\right)$ calculated using Eq. 5 for ultrafiltration experiments 2-6, 9 and 11 in Table 2 using a $100 \mathrm{kDa}$ cut-off $\mathrm{TiO}_{2}$ monochannel tubular ceramic membrane.

Figure 7. Colour reductions (\%D) for beet molasses at $\mathrm{pH} 3$ over time for experiments with two ultrafiltration runs using 1.5 or $3 \mathrm{~g} / \mathrm{L} \mathrm{NPAC} \mathrm{(NPAC1)} \mathrm{in} \mathrm{the} \mathrm{first} \mathrm{decolouration} \mathrm{run} \mathrm{and} 3 \mathrm{~g} / \mathrm{L}$ NPAC (NPAC2) in the second decolouration run. Operating conditions for ultrafiltration runs were: $100 \mathrm{kPa}$ of TMP, $4.24 \mathrm{~L} / \mathrm{h}$ of Qf and $25^{\circ} \mathrm{C}$.

Figure 8. Loss of decolouration capacity for NPAC after the first regeneration stage calculated using Eq. 3 for the ultrafiltration experiments with successive stages for the decolouration of beet molasses at pH 3 and subsequent charcoal regeneration. Experimental conditions for ultrafiltration runs: $100 \mathrm{kPa}$ of TMP, 2.5 or $5 \mathrm{~g} / \mathrm{L}$ of $\mathrm{C}_{\mathrm{NPAC}}$ and $25^{\circ} \mathrm{C}$. 
Figure 9. Comparison of recovery of coloured compounds $\left(\% \mathrm{R}_{\text {colour }}\right.$, Eq. 4$)$ from the exhausted NPAC in sodium hydroxide desorption solutions for the experiments depicted in Fig. 8. 


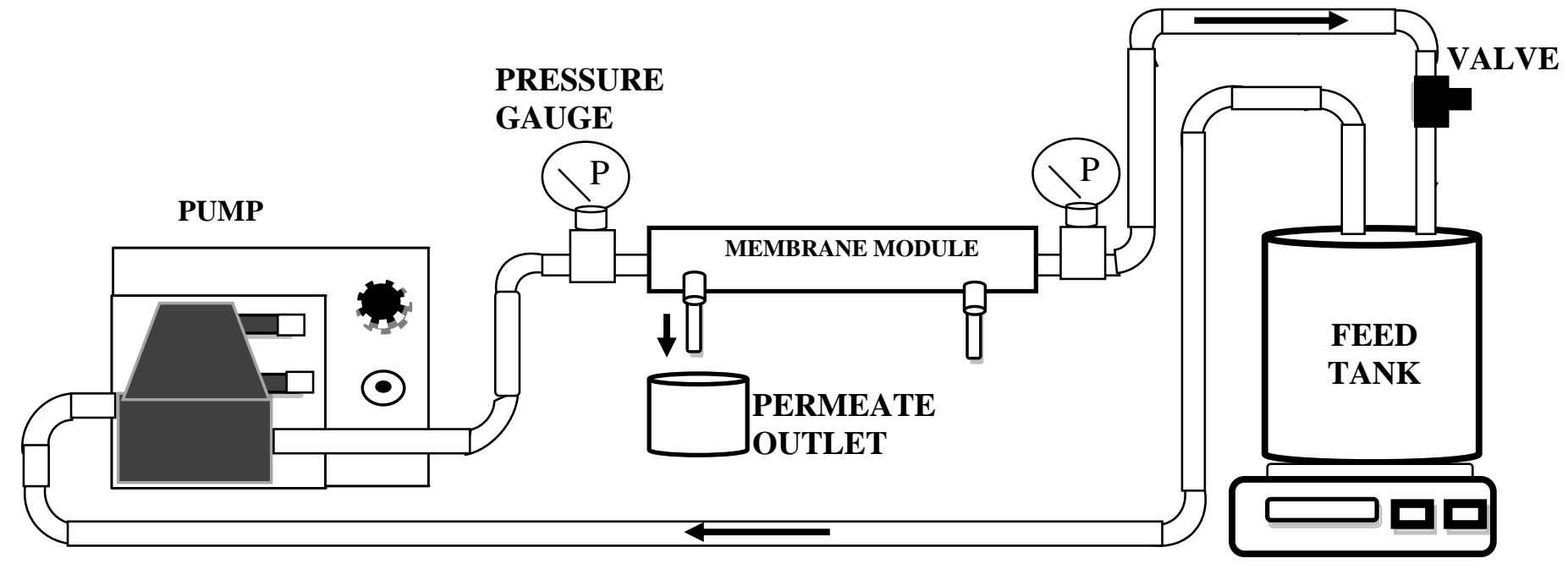

Figure 1 


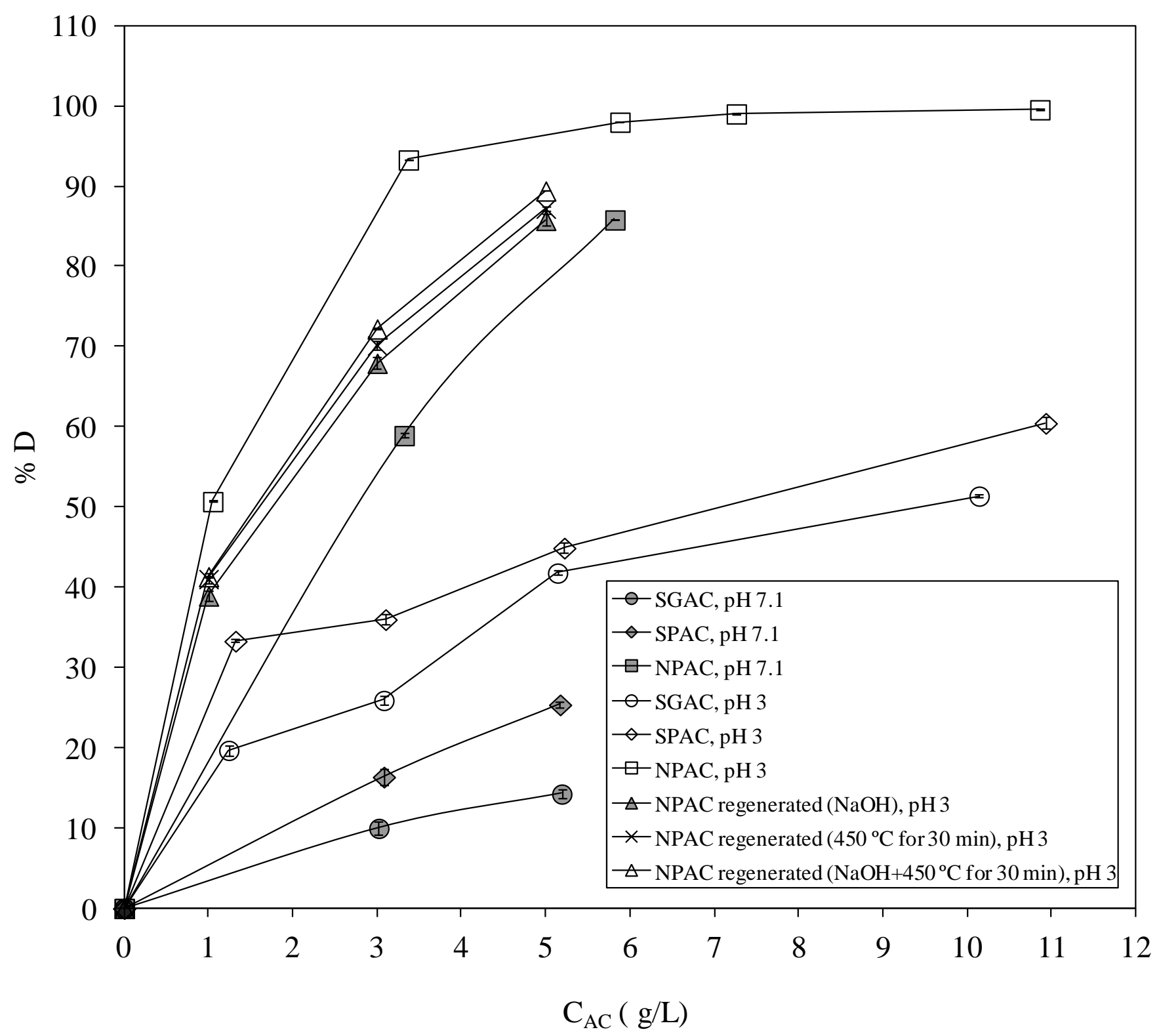

Figure 2 


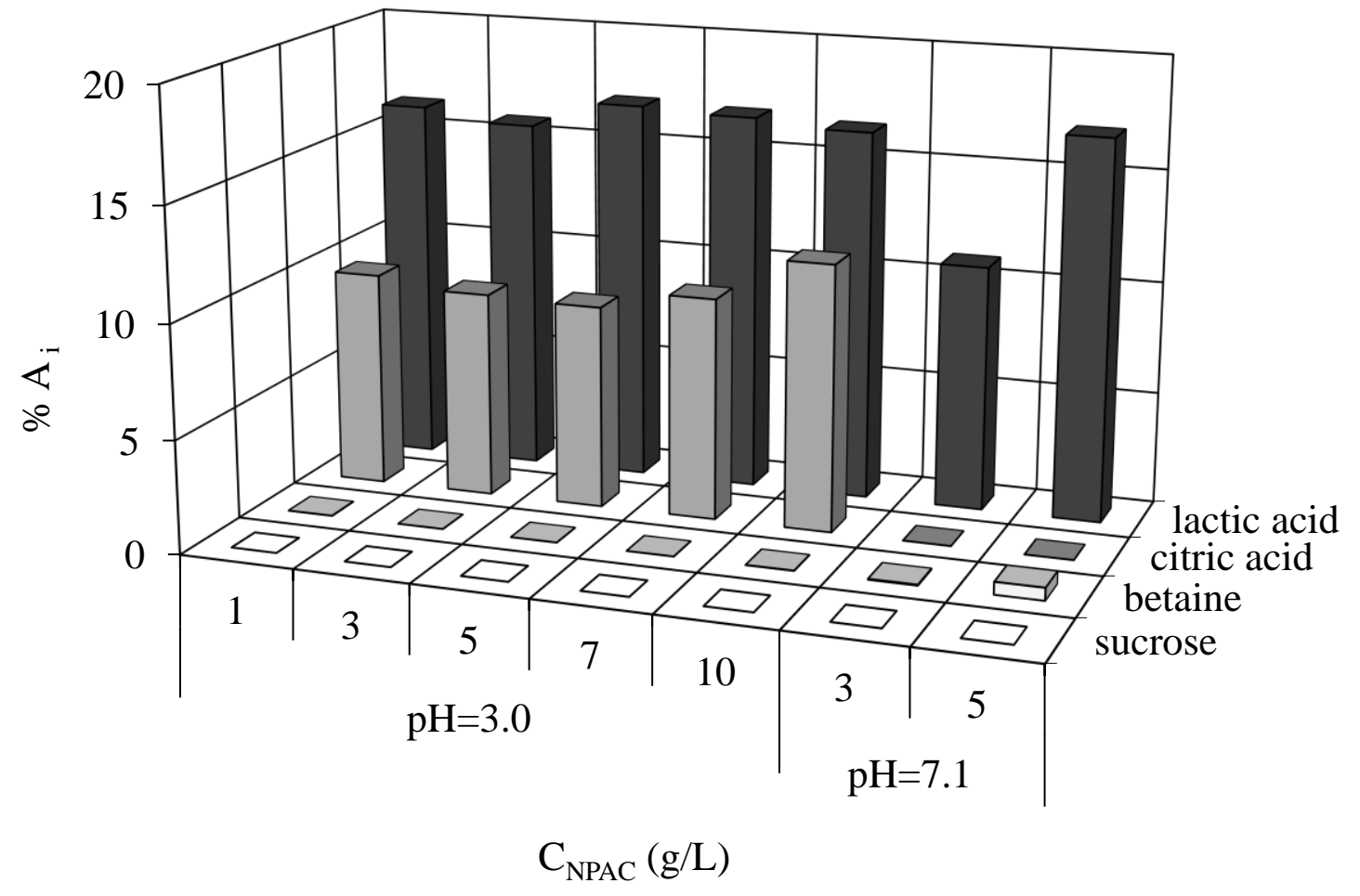

Figure 3 


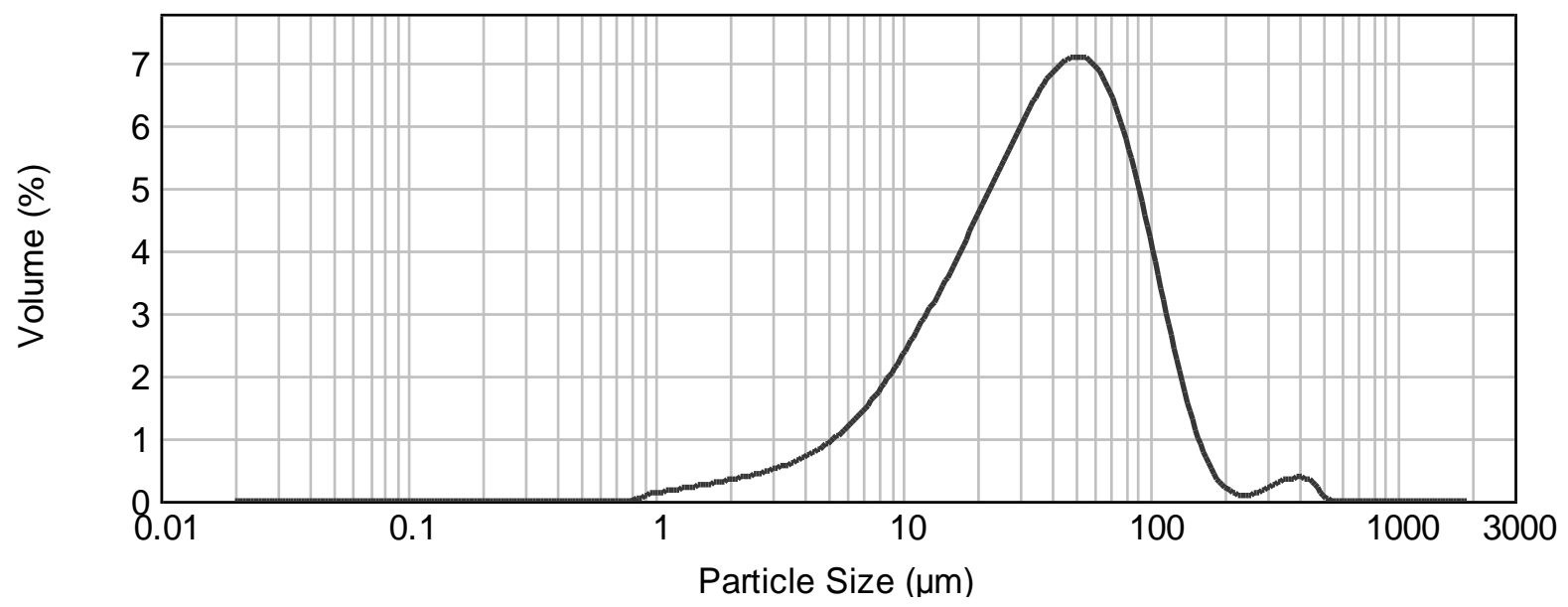

Figure 4 


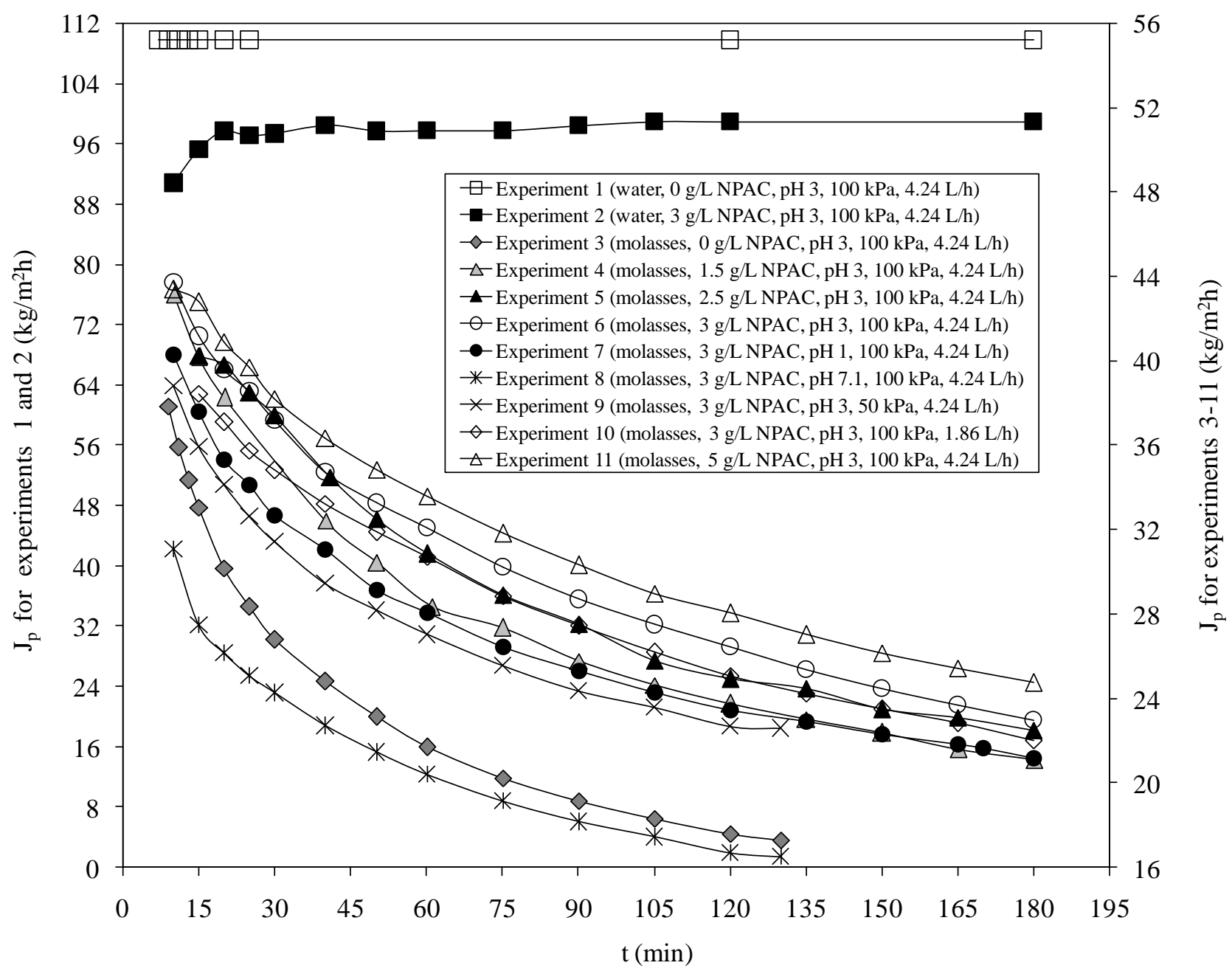

Figure 5(a) 


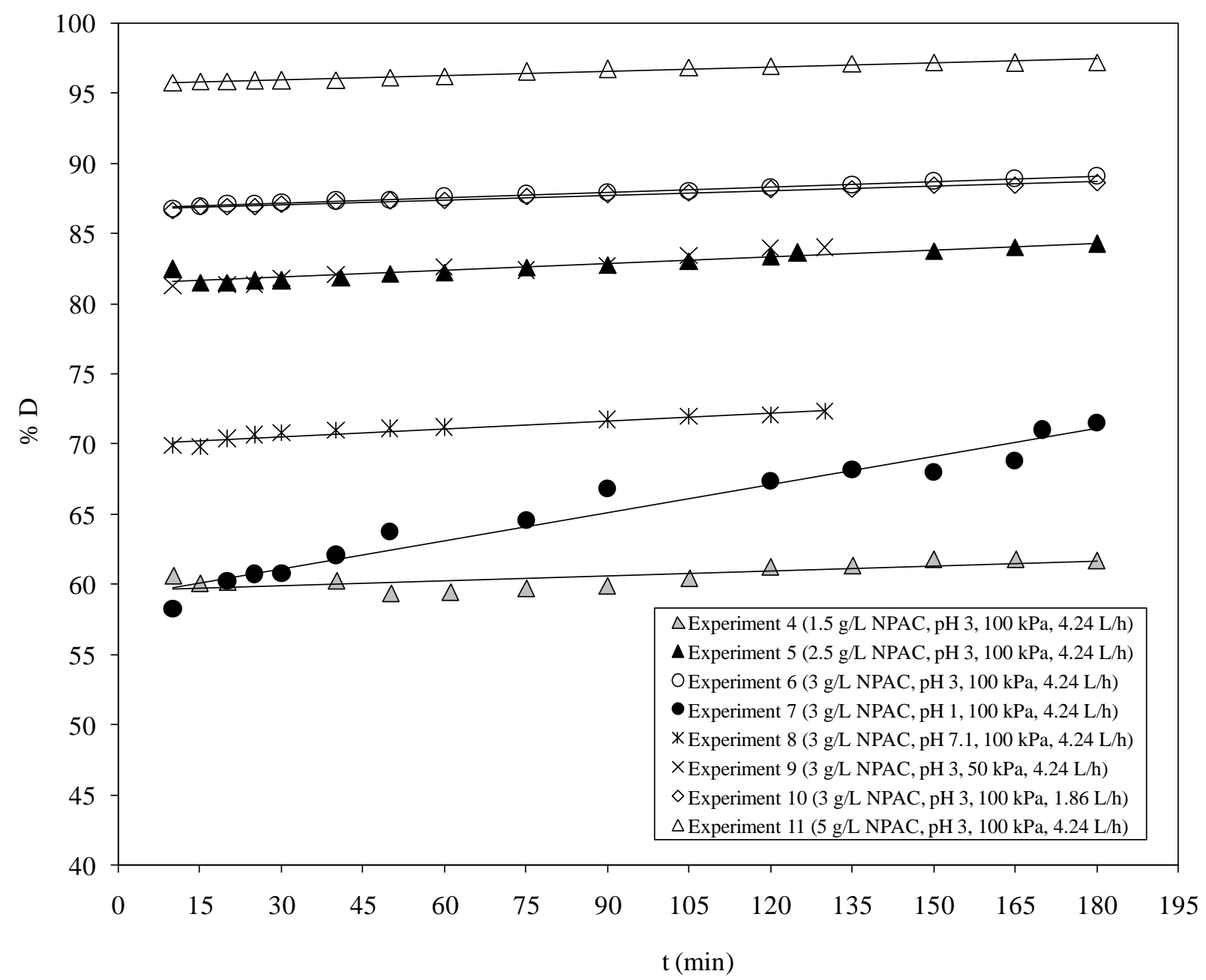

Figure 5(b) 


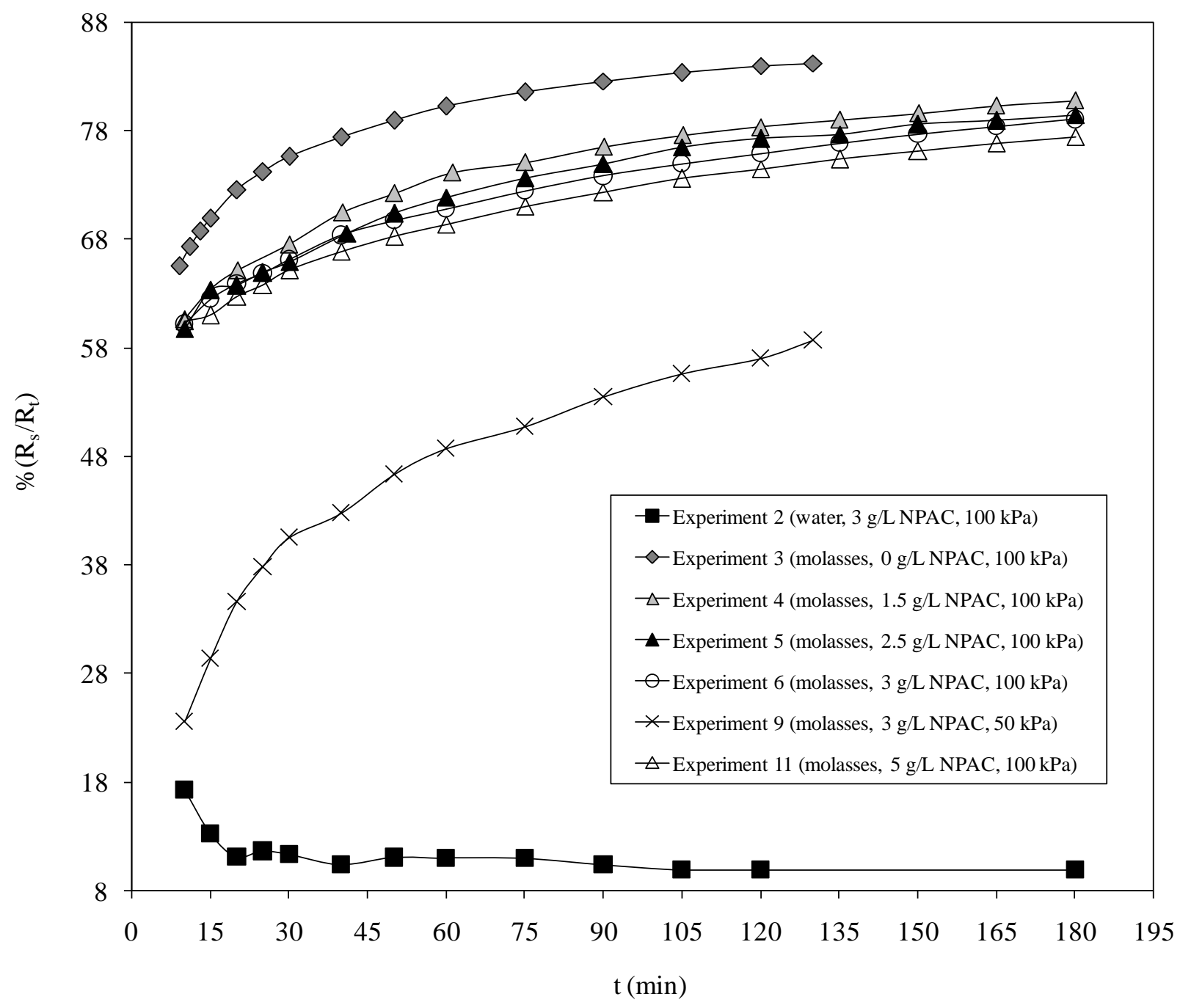

Figure 6 


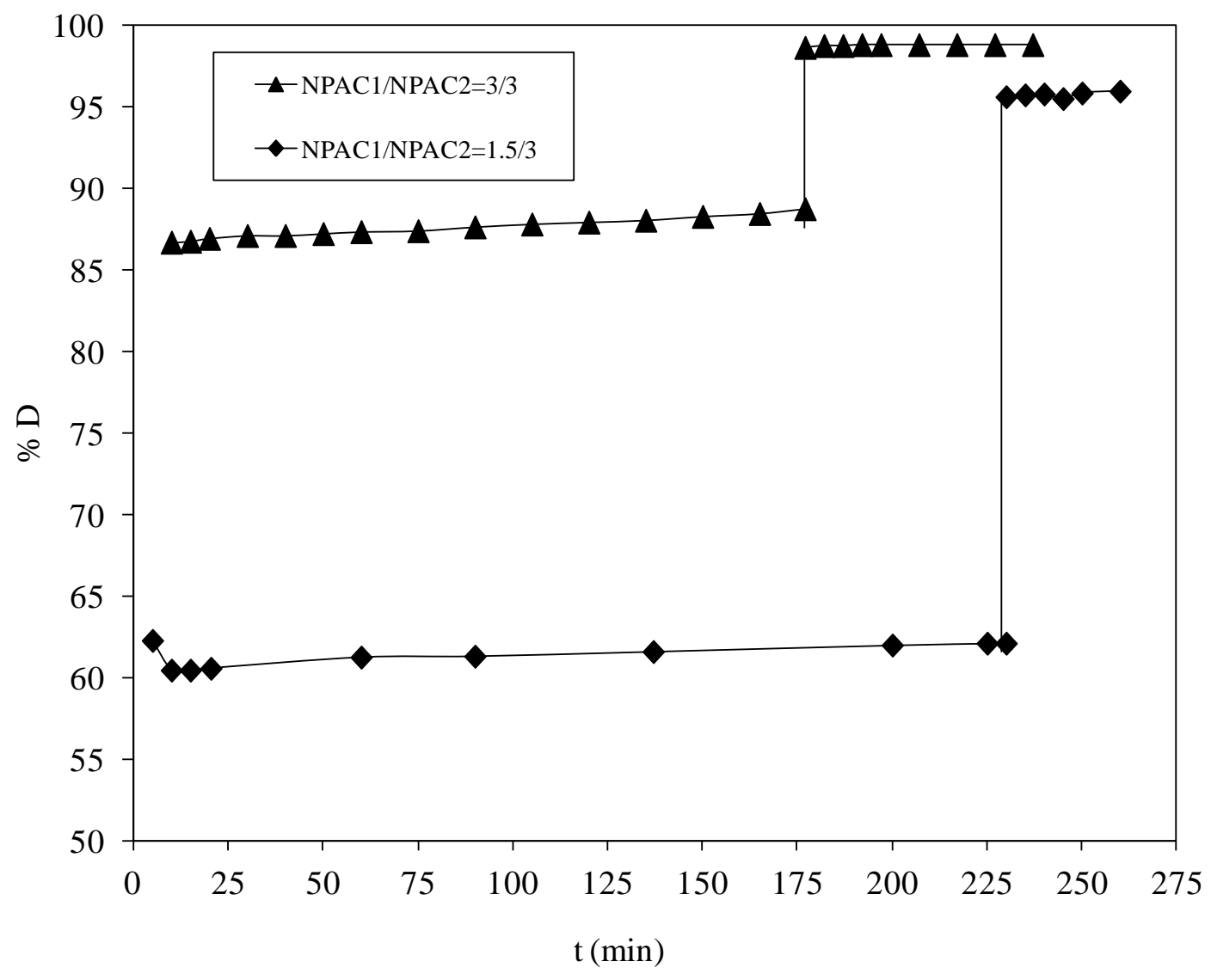

Figure 7 


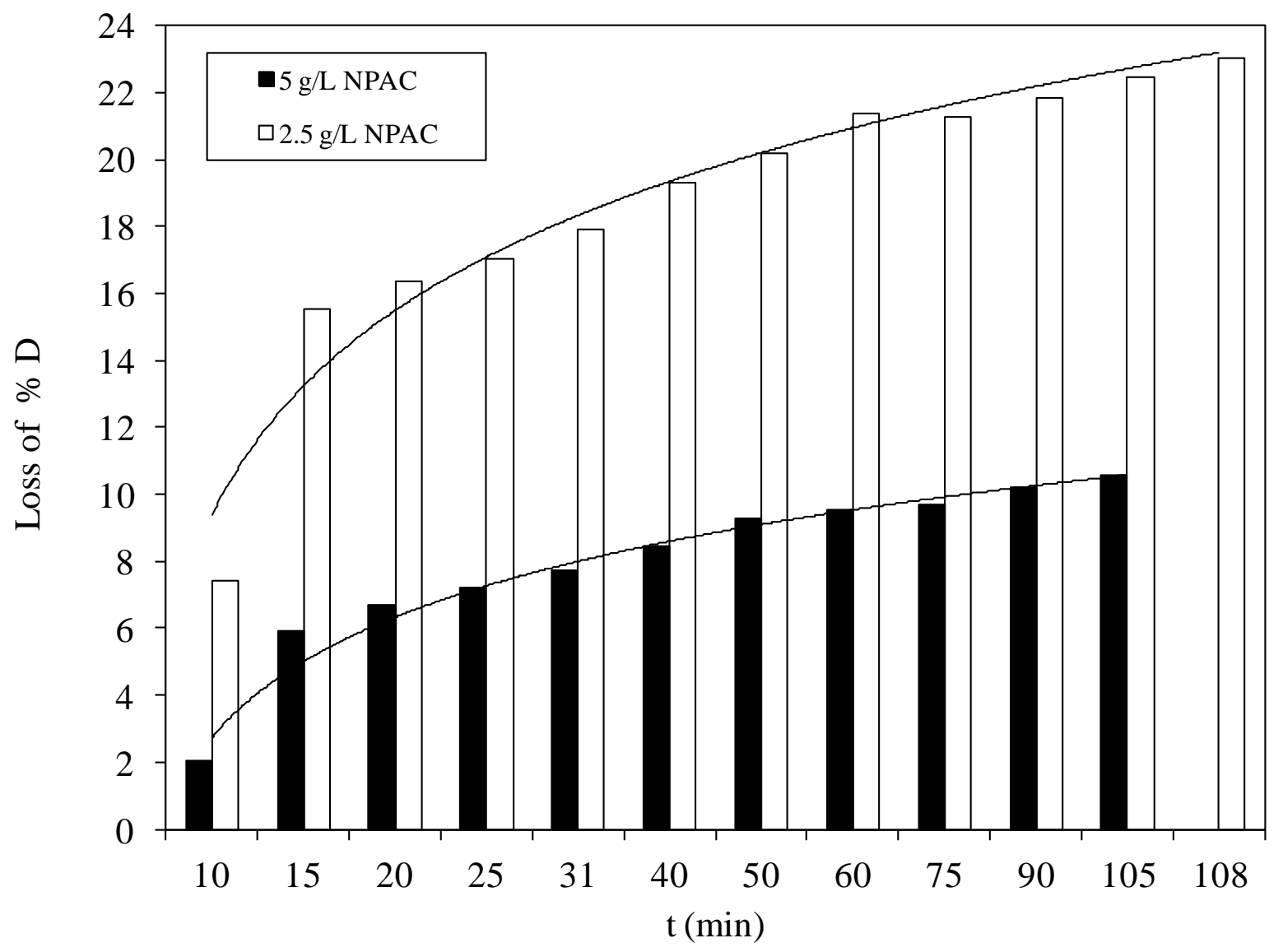

Figure 8 


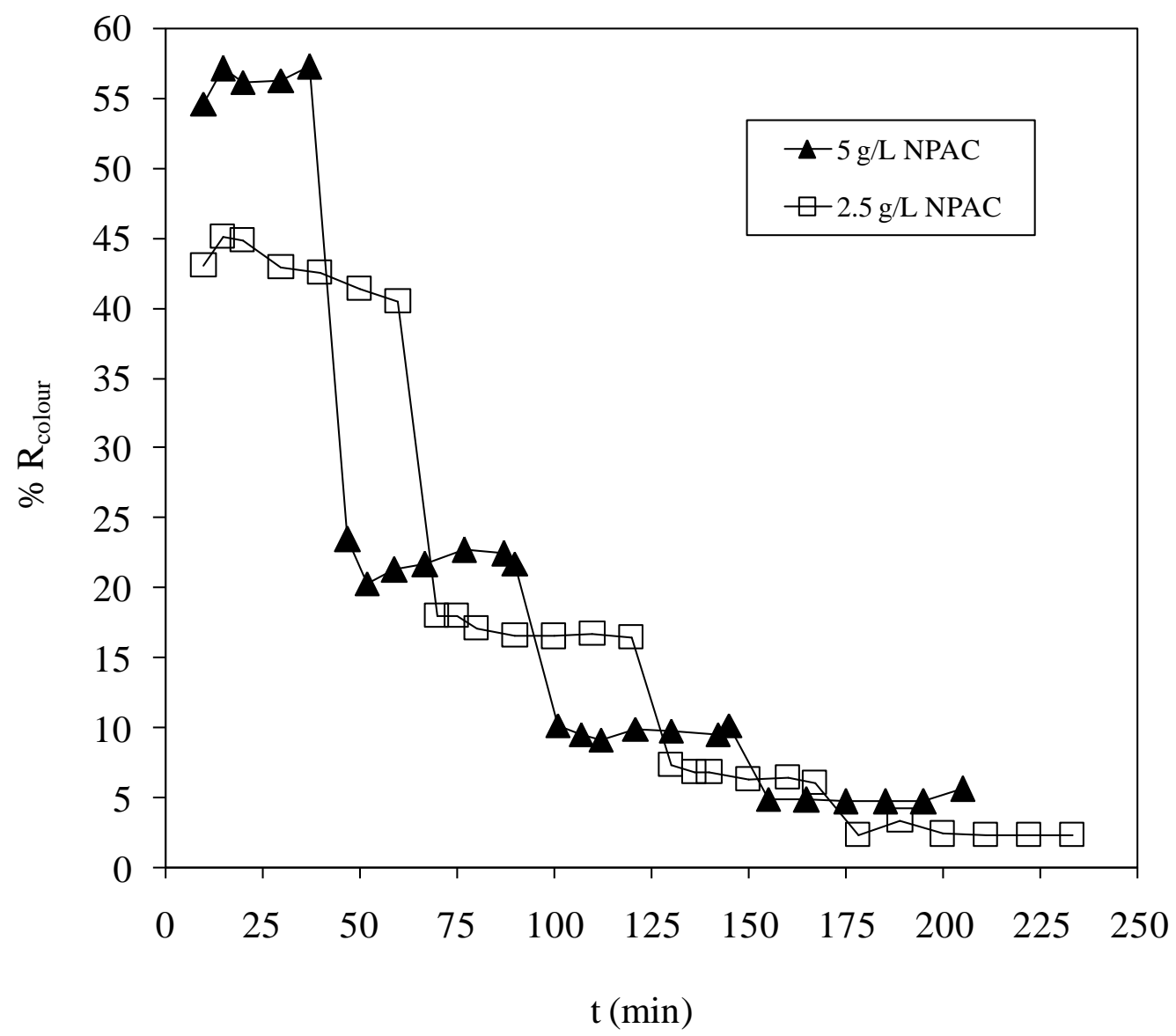

Figure 9 
Table 1. Colour reduction of beet molasses at equilibrium using NPAC $\left(\% \mathrm{D}_{1}\right)$ and NPAC after thermal regeneration $\left(\% \mathrm{D}_{2}\right)$, and loss of NPAC decolouration capacity after thermal regeneration at several experimental conditions.

\begin{tabular}{|c|c|c|c|c|c|c|}
\hline \multicolumn{2}{|c|}{$\begin{array}{l}\text { Thermal regeneration } \\
\text { conditions for } \\
\text { exhausted NPAC }\end{array}$} & \multicolumn{2}{|c|}{$\begin{array}{l}\text { Experimental conditions of the } \\
\text { equilibrium experiments with } \\
\text { NPAC and regenerated NPAC }\end{array}$} & \multirow[b]{2}{*}{$\begin{array}{c}\% \mathrm{D}_{1} \\
\text { (Eq. 1) }\end{array}$} & \multirow[b]{2}{*}{$\begin{array}{c}\% \mathrm{D}_{2} \\
\text { (Eq. 1) }\end{array}$} & \multirow[b]{2}{*}{$\begin{array}{l}\text { Loss of \%D } \\
\text { (Eq. 3) }\end{array}$} \\
\hline $\mathrm{t}(\mathrm{h})$ & $\mathrm{T}\left({ }^{\circ} \mathrm{C}\right)$ & $\mathrm{C}_{\mathrm{NPAC}}(\mathrm{g} / \mathrm{L})$ & $\mathrm{pH} / \mathrm{T}\left({ }^{\circ} \mathrm{C}\right)$ & & & \\
\hline 0.5 & 450 & 5 & $3 / 25$ & 98.0 & 87.2 & $11 \pm 2$ \\
\hline 0.5 & 450 & 3 & $3 / 25$ & 93.3 & 70.9 & $24 \pm 1$ \\
\hline 0.5 & 550 & 3 & $3 / 25$ & 93.3 & 49.4 & $47 \pm 1$ \\
\hline 1 & 450 & 5 & $3 / 25$ & 98.0 & 88.2 & $10 \pm 1$ \\
\hline 1 & 450 & 3 & $3 / 25$ & 93.3 & 71.6 & $23 \pm 1$ \\
\hline 1 & 550 & 3 & $3 / 25$ & 93.3 & 48.5 & $48 \pm 2$ \\
\hline 3 & 450 & 3 & $3 / 25$ & 93.3 & 56.9 & $39 \pm 3$ \\
\hline 5 & 450 & 3 & $3 / 25$ & 93.3 & 49.4 & $47 \pm 1$ \\
\hline
\end{tabular}


Table 2. Experimental results for ultrafiltration experiments with different feeds $(\mathrm{F})$ and operating conditions $\left(\mathrm{C}_{\mathrm{NPAC}}, \mathrm{TMP}, \mathrm{Qf}\right.$ and $\left.\mathrm{pH}\right)$, at $25 \pm 1{ }^{\circ} \mathrm{C}$. The contribution of the secondary resistance $\left(\%\left(\mathrm{R}_{\mathrm{s}} / \mathrm{R}_{\mathrm{t}}\right)\right)$ was calculated by Eq. 5. \%Do and $\mathrm{v}$ are, respectively, the intercept and slope of the linear fitting of $\% \mathrm{D}$ experimental data. These straight lines are shown in Figs. 5(b) and $r$ is the linear regression coefficient.

\begin{tabular}{|c|c|c|c|c|c|c|c|c|}
\hline & Experiment & $\begin{array}{c}\mathrm{C}_{\mathrm{NPAC}} \\
(\mathrm{g} / \mathrm{L})\end{array}$ & $\begin{array}{l}\text { TMP } \\
(\mathrm{kPa})\end{array}$ & $\begin{array}{c}\text { Qf } \\
(\mathrm{L} / \mathrm{h})\end{array}$ & $\begin{array}{c}\%\left(\mathrm{R}_{\mathrm{s}} / \mathrm{R}_{\mathrm{t}}\right) \\
\text { from } 15 \text { to } \\
120 \mathrm{~min}\end{array}$ & $\mathrm{v}\left(\mathrm{h}^{-1}\right)$ & $\%$ Do & $\mathrm{r}$ \\
\hline 1 & $(\mathrm{~F}=$ water $)$ & 0.0 & 100 & 4.24 & - & - & - & - \\
\hline 2 & $(\mathrm{~F}=$ water at $\mathrm{pH} 3)$ & 3.0 & 100 & 4.24 & 10.8 & - & - & - \\
\hline 3 & $(\mathrm{~F}=$ molasses at $\mathrm{pH} 3)$ & 0.0 & 100 & 4.24 & $69-83$ & - & - & - \\
\hline 4 & $(\mathrm{~F}=$ molasses at $\mathrm{pH} 3)$ & 1.5 & 100 & 4.24 & $68-80$ & 1.14 & 58.21 & 0.970 \\
\hline 5 & $(\mathrm{~F}=$ molasses at $\mathrm{pH} 3)$ & 2.5 & 100 & 4.24 & $62-75$ & 0.96 & 81.41 & 0.995 \\
\hline 6 & $(\mathrm{~F}=$ molasses at $\mathrm{pH} 3)$ & 3.0 & 100 & 4.24 & $62-75$ & 0.78 & 86.76 & 0.996 \\
\hline 7 & $(\mathrm{~F}=$ molasses at $\mathrm{pH} 1)$ & 3.0 & 100 & 4.24 & $66-77$ & 4.20 & 59.15 & 0.971 \\
\hline 8 & $(\mathrm{~F}=$ molasses at $\mathrm{pH} 7.1)$ & 3.0 & 100 & 4.24 & $75-84$ & 10.80 & 70.29 & 0.983 \\
\hline 9 & $(\mathrm{~F}=$ molasses at $\mathrm{pH} 3)$ & 3.0 & 50 & 4.24 & $29-56$ & 1.44 & 80.95 & 0.971 \\
\hline & $(\mathrm{F}=$ molasses at $\mathrm{pH} 3)$ & 3.0 & 100 & 1.86 & $65-76$ & 0.66 & 86.72 & 0.992 \\
\hline & $(\mathrm{F}=$ molasses at $\mathrm{pH} 3)$ & 5.0 & 100 & 4.24 & $61-73$ & 0.60 & 95.70 & 0.982 \\
\hline
\end{tabular}

